\title{
A Facile Technique of Sensing Adulteration in Emulsion: A Road to Safety
}

\author{
Biswas $\mathbf{R}^{1 *}$ and Karmakar $\mathrm{PK}^{2}$ \\ ${ }^{1}$ Applied optics and photonics laboratory, Department of Physics, Tezpur \\ University, India \\ ${ }^{2}$ Astrophysical Plasma Lab, Department of Physics, Tezpur University, India
}

*Corresponding author: Rajib Biswas, Applied Optics and Photonics Laboratory,

Research Article

Volume 3 Issue 5

Received Date: October 12, 2019

Published Date: November 11, 2019

DOI: $10.23880 /$ eoij-16000218

Department of Physics, Tezpur University, Tezpur-784028, India, Email: rajib@tezu.ernet.in

\section{Abstract}

Urea is a regular contaminant used in raw milk. Excess intake of urea-contaminated milk produces various health hazards. The key experimental challenge is to develop a rapid and inexpensive urea detection technique. Despite multitude of analytical schemes, they fall short either in rapid sensing or in cost effectiveness. In the quest of solutions, we unravel the systematic and procedural colorimetric quantification of urea through pristine gold nanoparticles. The sensing provides a limit of detection of $0.03 \mathrm{mg} / \mathrm{ml}$, which is well below the permissible range of the World Health Organization (WHO). Being endowed with an excellent linearity of $\sim 0.99$ and cost effectiveness, the sensing unit possesses a good reproducibility with potential scope in real sample analysis.

Keywords: Safety; Milk; Food Industries; Urea

\section{Introduction}

Maintaining quality of food products has become a major challenge for producers as well as regulatory agencies. Several protocols are followed in keeping nutritional elements intact. Despite existence of stringent regulation conditions in food industries, the compositional analysis reveals the presence of some contaminating elements leading to a loss of nutritional order. The presence of adulterating species makes the whole thing unusable. Milk is a vital food product, which caters from infants to adults. It is an emulsion of fat in watery solution of sugars, mineral salts and proteins in colloidal solutions. It is the base of whole dairy industry.

It is known that the milk is one of the most frequently adulterated item in the country. In countries like India,
Pakistan, China, Bangladesh etc., the demand of milk exceeds the supply, which is fuelled by rising human population and urbanization. Consequently, the producers and vendors are tempted to adulterate milk. Several reports of adulteration in milk have been reported recently [1-9]. The common chemicals adulterants, which have been reported in milk, are sodium hydroxide, formalin, hydrogen peroxide, cane sugar, starch, gelatine, synthetic dyes, soap detergents and urea [10-18]. Among them, urea is frequently used in raw milk as per reports [4-19].

The typical concentration of urea in milk is $18-40$ $\mathrm{mg} / \mathrm{dl}[1,4,9-13]$. Urea is a normal constituent of milk and it is a major part (55\%) of the non-protein nitrogen of milk. However, for commercial benefits chemicals like urea, caustic soda, refined oil and detergents are used to 


\section{Ergonomics International Journal}

adulterate the milk. These adulterations decrease the nutritive value of milk and pose a great threat to human health [1]. A cut off limit of urea in milk is normally accepted at $70 \mathrm{mg} / \mathrm{dl}$. The presence of urea above the cut off limit in milk can cause health problems such as indigestion, acidity, ulcers, cancer etc. Hence, quantitative detection and estimation of urea play a significant role in dairy industries and food processing technology.

A variety of analytical techniques has been developed for the determination of urea, although no single technique is that versatile to provide satisfactory results in all areas [19-32]. Methods are often categorized as Direct or Indirect [13]. The term indirect refers to the enzymatic degradation of urea prior to detect. Direct procedures have been defined as those resulting in a coloured product, which indicates the presence of urea, but this method, cannot give quantitative measurements. Various analytical techniques available to detect urea are based on colorimetric or chromatographic methods, which consume much time to get the species analysed and are too tedious and expensive to be used. Although lacking the inherent selectivity of the UV absorbance measurement also offers a convenient method of detection when coupled with chromatographic or electrophonetic separation [14]. Infrared spectrometry is another technique for the dairy industry research, where this technique is already employed for analysis of milk fat and proteins.

Recently several methods for melamine detection, including chromatographic methods [9-14], which consume much time to get the species analysed and are too tedious and expensive to be used. Also highperformance liquid chromatography and potentiometric and electrochemical methods are time consuming, are expensive and need trained people [4-8]. Some authors have also proposed nanotechnology based methods [911]. In the current study, we aim to synthesize gold nanoparticles (AuNPs) and exploit them for visual detection of urea in milk as a colorimetric probe. The citrate stabilized gold nanoparticles are wine red in colour in the absence of urea, whereas in the presence of urea they change to blue because urea causes the aggregation of nanoparticles.

\section{Experimental Procedures}

\section{Materials}

Chloroauric acid, Trisodium citrate were purchased from Sigma Aldrich (USA). All the chemicals are used without further purification. For controlling the $\mathrm{pH}$ of the solutions, $0.01 \mathrm{M} \mathrm{NaOH}$ solution was used. Aqua regia was used to clean the all glass wear. Ultra pure Milipore water had been utilized in all analysis.

\section{Synthesis of nanoparticles}

All glassware used in preparation of AuNPs were dipped in freshly prepared aqua regia $\left(\mathrm{HNO}_{3} / \mathrm{HCl}, 1: 3\right)$ and rinsed thoroughly. AuNPs were prepared by the citrate reduction method. Chloroauric acid $(100 \mathrm{ml}, 1 \mathrm{mM})$ was boiled in a $250 \mathrm{ml}$ round-bottom flask. Then, $5 \mathrm{ml}$ of Trisodium citrate $(38.8 \mathrm{mM})$ was added rapidly into boiling Chloroauric acid solution with rapid stirring. The pale yellow colour of Chloroauric acid gradually changed to a wine red colour within 3 minutes. Stirring was continued for 15 minutes. The wine reddish AuNPs formed were then cooled to room temperature and stored at $4^{\circ} \mathrm{C}$ for further use.

\section{Colorimetric Sensing Protocol}

Initially, $4.0 \mathrm{~mL}$ raw milk (real sample) has been taken in a $10 \mathrm{~mL}$ centrifuge tube and $1.2 \mathrm{~mL}$ of $300 \mathrm{~g} / \mathrm{L}$ Trichloroacetic acid (TCA) has been added. Subject to cetritrifugation for 5 minutes, the supernatants are then transferred into another centrifuge tube. Afterwards, the $\mathrm{pH}$ is adjusted to 7 with small amounts of $6 \mathrm{M} \mathrm{NaOH}$. Finally, the filtrate is extracted. Subsequently, $100 \mu \mathrm{L}$ of the obtained filtrate has been added to $400 \mu \mathrm{L}$ GNPs solution and kept at room temperature. On addition of traceable amount of urea, there arises distinguishable colour change from the pristine conditions. Finally, absorption spectra of the reacted solution were recorded with $1 \mathrm{~cm}$ path length cell. The schematic of the elaborated procedure is shown in Figure 1.

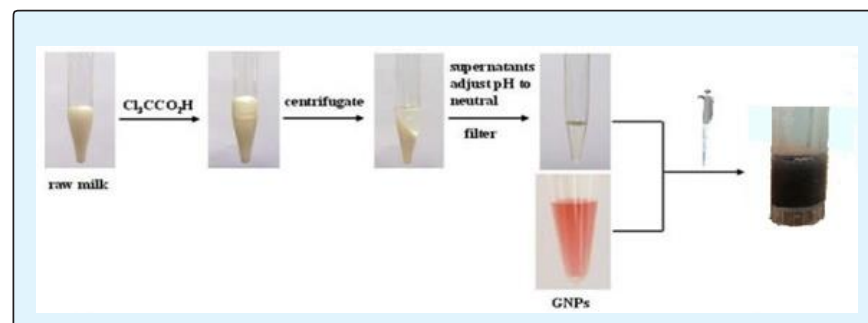

Figure 1: Schematic representation of the analytical process for determining urea in raw milk.

\section{Results and Discussion}

\section{Principle of Urea Detection using AuNPs}

The principle of urea detection is based on the surface stabilization of AuNPs. AuNPs are stabilized by negatively charged citrate ions. The negatively charged citrate ions 
constitute an electrostatic layer on AuNPs, keep the nanoparticles separated, and stable in aqueous solution. However, in presence of urea, there arises destabilization and aggregation of nanoparticles, which further increases with concentration of urea. Urea possesses two amide groups $\left(-\mathrm{NH}_{2}\right)$ that interact with AuNPs through the legend exchange with negatively charged citrate ions. This aggregation results in a red-to-blue colour change, as depicted in Figure 2(a). We have taken the UV-vis spectra of coolorimetric responses with varying concentrations of urea whcih facilitate the ease quantification of urea contamination in milk. Corresponding spectra are shown in Figure 2(b).

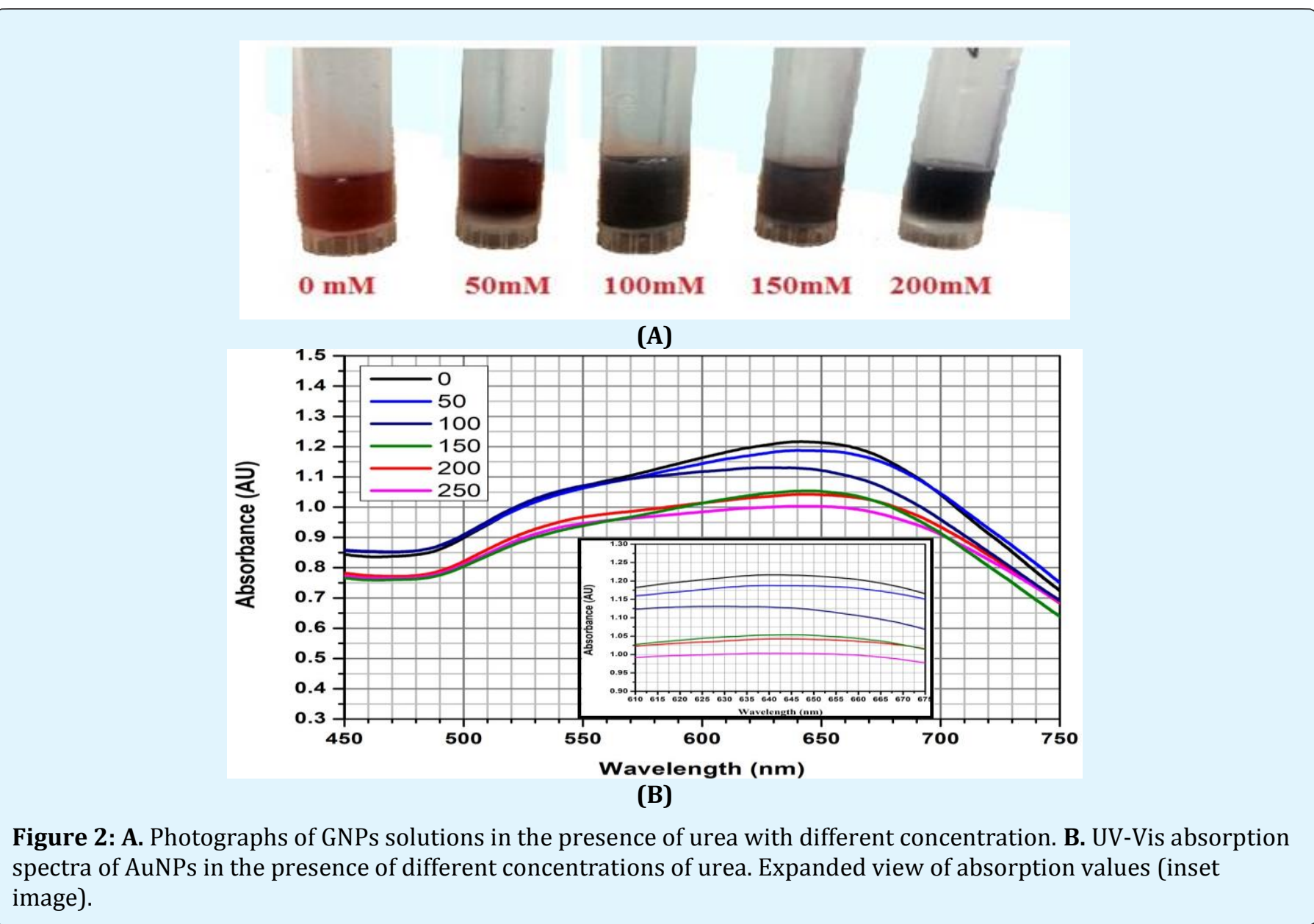

The colorimetric sensing produces a good linearity of the order $\sim 0.99$. We further observe the reproducibility of the results and found identical color change in specified proportions. As the sensing is done in controlled condiotions, the chance of other adulterating species is close to nill, except urea.

\section{Optimization of Colorimetric Response}

The current colorimetric method is based on urea catalyzed aggregation of AuNPs. The aggregation of AuNPs can be impacted by factors such as media $\mathrm{pH}$ and reaction time. Therefore, we investigated these parameters for making this method highly stable and reproducible. The $p H$ of media is an important factor influencing the stability of AuNPs. When AuNPs and milk sample are prepared, we utilized Trichloroacitic acid (TCA); the $\mathrm{pH}$ of colloidal AuNPs solution is approximately 2. AuNPs exhibit best stability near neutral. When $p H$ of filtrate from milk sample was highly acidic or basic, it caused the abrupt colour change of AuNPs even in the absence of urea. When $p H$ of filtrate was adjusted to 7 using $6 \mathrm{M} \mathrm{NaOH}$, no colour change was observed in absence of urea, whereas the presence of urea caused a significant colour change of AuNPs. Thus, the $p H$ of media was kept at 7.0 for all experiments. 


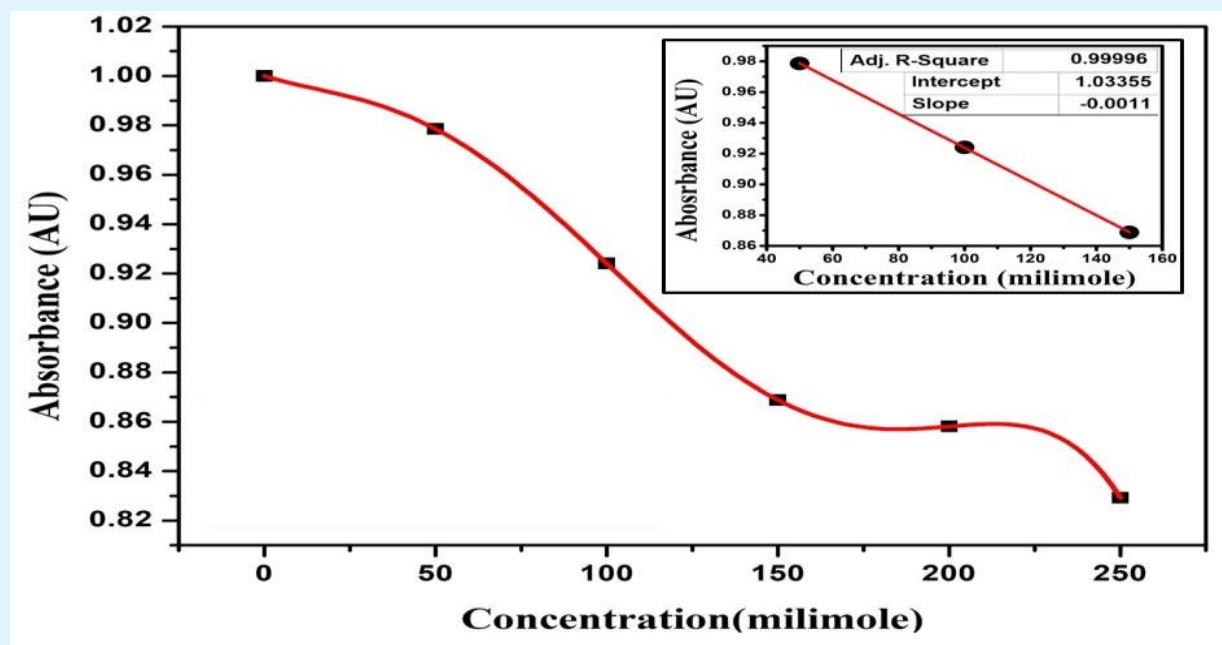

Figure 3: Absorbance vs. urea concentration of urea. (Inset shows the linearly fitted absorption spectra).

As shown in Figure 4, we performed a thorough analysis of absorbance with respect to two wavelengths From UV-Vis curves; we have taken two wavelengths 660 and 740 . When the corresponding absorbance values of these two wavelengths are taken into account, we find a linear rise with increase in concentration of urea in raw milk. This profile validates the functioning of the colorimetric assessment of urea contamination in raw milk.

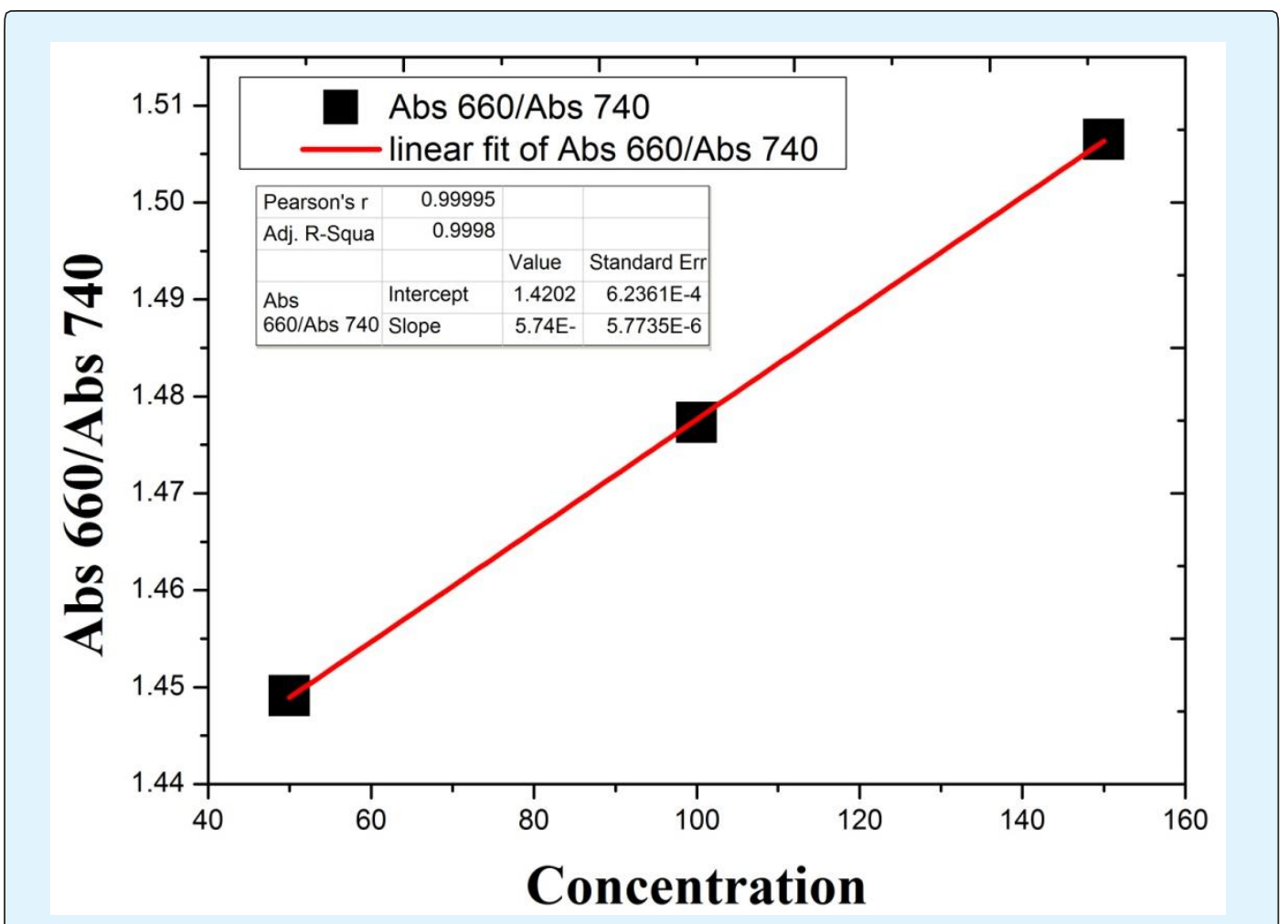

Figure 4: Calibration curve of urea detection Absorption ratio vs. Concentration of urea. 


\section{Ergonomics International Journal}

\section{Performance Assessment}

The limit of detection (LOD) of the urea was determined by spiking milk with increasing concentration of urea (0-250 mM). When the urea-spiking sample was added to AuNPs complex, concentration dependent aggregation was observed. The aggregation was monitored by change in the absorbance values of AuNPs. A linear correlation was obtained between absorbance and urea concentration ranging from 50 to $150 \mathrm{mM}$ with regression value $\left(R^{2}\right)$ of 0.99 (Figure 4). As per estimates, the detection limit of the present method for urea is $0.03 \mathrm{mM}$ and similarly, the limit of quantification has been determined to be $1.2 \mathrm{mM}$ following the available techniques [33-41]. It is quite apparent that absorption values are accompanied by gradual decline with increasing concentration of urea. The scheme provides a well-defined linear range of $50 \mathrm{mM}$ to $150 \mathrm{mM}$ of urea concentration. In the same note, the precision of the sensing scheme emerges to be 0.92 (normalised absorption value) $+100 \mathrm{mM}$. Apart from this, we find convergence of absorption estimates corresponding to increasing as well as decreasing concentrations of urea when the cycle is repeated over a long span of time with minimal deviation. This substantiates the stability of estimates done during the analysis, thereby validating the sensing approach. As the whole process is through visual eye detection with affirmation form UV-Vis spectroscopy, it is envisioned that it will help in fabrication of more portable arrays for other contaminants found in raw milk.

\section{Conclusion}

In this work, we have demonstrated an AuNP-based colorimetric method for the detection of urea contamination in raw milk. When urea contaminated milk interacts with AuNPs, there emerges colour change red/violet, detectable even without any aid of sophisticated instrument. Through varying concentrations of urea in milk, we have found considerable amplitude variation in absorption spectra. Overall, this colorimetric sensing scheme can detect traces of urea in milk down to a minimum value of 0.03 $\mathrm{mg} / \mathrm{ml}$. The reported experimental scheme could have enough potential to be applied for the impurity analysis in the case of other fodder products through tuning the shape and size of nanoparticles properly.

\section{Conflict of Interest}

The authors declare no conflict of interest.

\section{Acknowledgement}

The present work was executed without any external funding. It was solely funded from the personal funds from authors.

\section{References}

1. Singh A, Sharma J, Bhatt SR (2011) Detection of illeffects of urea adulterated milk in Varanasi. Food Science Research Journal 2(1): 46-49.

2. Das S, Sivaramakrishna M, Biswas K, Goswami B (2011) Performance study of a constant phase angle based impedance sensor to detect milk adulteration. Sensors and Actuators A: Physical 167(2): 273-278.

3. Zhang XF, Zou MQ, Qi XH, Liu F, Zhu XH, et al. (2010) Detection of melamine in liquid milk using surfaceenhanced Raman scattering spectroscopy. J Raman Spectrosc 41(12): 1655-1660.

4. Santos PM, Pereira-Filho ER, Rodriguez-Saona LE (2013) Application of Hand-Held and Portable Infrared Spectrometers in Bovine Milk Analysis. J Agri Food Chem 61(6): 1205-1211.

5. (1998) Synthetic milk and its Detection. Food Processing World.

6. Dai X, Zhao Y, Li M, Fang X, Li X, et al. (2013) Determination of urea in milk by liquid chromatography-isotope dilution mass spectrometry. Analytical Letters 45: 1557-1565.

7. Banupriya $\mathrm{P}$, Chaitanya $\mathrm{R}$ Shetty, Supriya TV, Varshitha V (2014) Comparison of different methods used for detection of urea in milk by quantification of ammonia. Int J Adv Res Elect, Electron Instrum Eng 3(3): 7858-7863.

8. Arvind Singh, Gulab C, Aggarwal A, Kumar P (2012) Adulteration Detection in Milk. Res News for $U$ (RNFU) 5: 52.

9. Nascimento CF, Santos PM, Pereira-Filho ER, Rocha FRP (2017) Recent Advances on Determination of Milk Adulterants. Food Chemistry 221: 1232-1244.

10. Poonia A, Jha A, Sharma R, Singh HB, Rai AK, et al. (2017) Detection of adulteration in milk: A review. Int J Dairy Technology 70 (1): 23-42. 


\section{Ergonomics International Journal}

11. Tian H, Zheng N, Wang W, Cheng J, Li S, et al. (2016) Integrated Metabolomics Study of the Milk of Heatstressed Lactating Dairy Cows. Scientific Reports 6: 24208.

12. Kowsar R, Keshtegar B, Marey MA, Miyamoto A (2017) An autoregressive logistic model to predict the reciprocal effects of oviductal fluid components on in vitro spermophagy by neutrophils in cattle. Scientific Reports 7(1): 4482.

13. Hilding-Ohlsson A, Fauerbach JA, Sacco NJ, Bonetto MC, Cortón E (2002) Voltamperometric Discrimination of Urea and Melamine Adulterated Skimmed Milk Powder. Sensors 12(9): 12220-12234.

14. Trbović D, Petronijević R, Đorđević V (2017) Chromatography methods and chemometrics for determination of milk fat adulterants. IOP Conf. Series: Earth and Environmental Science 85: 012025.

15. Gunnery KS (1979) Additives in milk and their detection. Ind Dairyman 39(9): 665-669.

16. Paul PS, Simon SW, Lim KF (2002) Analytical methodology for the determination of urea: current practice and future trends, Trends in Analytical Chemistry 21(5): 389-400.

17. Gutiérrez M, Alegret S, del Valle M (2007) Potentiometric bioelectronic tongue for the analysis of urea and alkaline ions in clinical samples. Biosensor \& Bio electron 22(9-10): 2171-2178.

18. Spenser K, Clin A (1986) Analytical reviews in clinical biochemistry: the estimation of creatinine. Biochem 23(1): 1-25.

19. Abdel LMS, Guibault GG (1990) Fluorometric determination of urea by flow injection analysis. J Biotechnol 14(1): 53-61.

20. Jenkins DM, Delwiche MJ, DePeters EJ, BonDurant RH (2002) Refinement of pressure assay for milk urea nitrogen. J Dairy Sci 83(9): 2042-2048.

21. Verma N, Sihgh M (2003) A disposable microbial based biosensor for quality control in milk. Biosens. \& Bioelectron 18: 1219-1224.

22. Renny EF, Daniel DK, Krastanov AI, Zachariah CA, Elizabeth R (2005) Enzyme based sensor for detection of urea in milk. Biotechnol \& Biotechnol Eq 19(2): 198-201.
23. Luong JHT, Bouvrette P, Male KB (1997) Developments and applications of biosensors in food analysis. Trends Biotechnol 15: 369-377.

24. Singh M, Verma N, Garg AK, Redhu N (2008) Urea biosensors. Sens \& Act B: Chem 134(1): 345-351.

25. Jonker JS, Kohn RA, Erdman RA (1998) Using milk urea nitrogen to predict nitrogen excretion and utilization efficiency in lactating dairy cows. J Dairy Sci 81(10): 2681-2692.

26. Trivedi UB, Lakshminarayana D, Kothari IL, Patel NG, Kapse HN, et al. (2009) Potentiometric biosensor for urea determination in milk. Sens \& Act B: Chem 140(1): 260-266.

27. Butler WR, Calaman JJ, Beam SW (1996) Plasma and milk urea nitrogen in relation to pregnancy rate in lactating dairy cattle. J Anim Sci 74(4): 858-865.

28. Kavitha P, Bector BS, Sharma V (2001) Urea content of milk of Murrah breed of buffaloes. Buffalo Newsletter 16: 10-12.

29. DePeters EJ, Ferguson JD (1992) Nonprotein nitrogen and protein distribution in the milk of cows. J Dairy Sci 75(11): 3192-3209.

30. Butler WR, Calaman JJ, Beam SW (1996) Plasma and milk urea nitrogen in relation to pregnancy rate in lactating dairy cattle. J Anim Sci 74(4): 858-865.

31. Larson SF, Butler WR, Currie WB (1997) Reduced fertility associated with low progesterone postbreeding and increased milk urea nitrogen in lactating cows. J Dairy Sci 80(7): 1288-1295.

32. Lakard B, Herlem G, Lakard S, Antoniou A, Fahys B (2004) Urea potentiometric biosensor based on modified electrodes with urease immobilized on polyethylenimine films. Biosens \& Bioelectron 19(12): 1641-1647.

33. Baruah BS, Biswas R, Deb P (2019) A green colorimetric approach towards detection of arsenic (III): a pervasive environmental pollutant. Optics and Laser Technology 111: 825-829.

34. Baruah BS, Biswas R (2019) Mangifera indica leaf extract mediated gold nanoparticles: a novel platform for sensing of As(III). IEEE Sensors Letter 3(3). 


\section{Ergonomics International Journal}

35. Baruah BS, Biswas R (2018) Localized surface plasmon resonance based $U$-shaped optical fiber probe for the detection of $\mathrm{Pb} 2+$ in aqueous medium. Sensors and Actuators B Chemical 276: 89-94.

36. Baruah BS, Biswas R (2018) An optical fiber based surface plasmon resonance technique for sensing of lead ions: A toxic water pollutant, in press, Optical Fiber Technology 46: 152-156.

37. Biswas R (2019) Adulteration in milk: Agrowing concern. Journal of Veterinary Sciences 9(1): 1-2.

38. Boruah BS, Daimari NK, Biswas R (2019) Functionalized silver nanoparticles as an effective medium towards tracedetermination of arsenic (III) in aqueous solution. Result in Physics 12: 2061-2065.
39. Boruah BS, Biswas R (2019) Probing lead ion contamination in aqueous solution through bioinspired surface modification of gold nanoparticles on D-shaped fiber. In IEEE Transactions on Nanotechnology 18: 770-775.

40. Paul D, Biswas R (2018) Facile fabrication of sensing set-up for size detection of nanoparticles. IEEE Transactions on Nanotechnology 17(3): 596-602.

41. Paul D, Biswas R, Boruah BS (2019) Influence of probe geometry of optical fibers in sensing volatile liquids through localized surface plasmon resonance. Arxiv. 